\title{
Early assessment of genotypic variation in growth and nitrogen fixation in Faidherbia albida/rhizobium symbiosis
}

\author{
Mahamadi DIANDA * , B. Kadidia SANON, O. Boukari DIALLO and Salawu ASIMI \\ Institut de l'Environnement et de Recherches Agricoles, Département Productions Forestières, \\ 03 BP 7047 Ouagadougou 03, Burkina Faso. \\ *Corresponding author, E-mail: dmahamadi@yahoo.fr; Tel.: (226) 503340 98; Fax: (226) 50315003
}

\begin{abstract}
To enhance the benefits from $\mathrm{N}_{2}$-fixing symbiosis in low nitrogen fixers such as Faidherbia albida, knowledge is needed on how genotypes of both the host and its bacterial partner interact to influence $\mathrm{N}$ fixation-related traits of the host legume. A greenhouse experiment was carried out to investigate the variability of several traits with respect to provenance, rhizobial strain and their interactions. Four West African provenances of $F$. albida were inoculated with five proven effective strains and grown for two months. Provenance $\mathrm{x}$ strain interactions were significant only for shoot $\mathrm{N}$ concentration $(\% \mathrm{~N})$ and total shoot $\mathrm{N}$ uptake but their contributions to total phenotypic variances were rather low (6-10\%). Because of large differences among provenances in growth performance the host genotype showed the greatest contribution $(70.7 \%)$ to the variability in total shoot $\mathrm{N}$ uptake. Variability in $\% \mathrm{~N}$ in turn was mostly related to strain effectiveness $(71.2 \%)$. These results suggest that under conditions of $\mathrm{N}$ deficiency, growth performance and shoot $\mathrm{N}$ concentration provide reliable selection criteria when screening for improved $\mathrm{N}_{2}$-fixation in $F$. albida.

(C) 2009 International Formulae Group. All rights reserved.
\end{abstract}

Keywords: rhizobia, Faidherbia, provenance, variability, interaction, $\mathrm{N}_{2}$-fixation.

\section{INTRODUCTION}

In most arid and semi-arid areas of Africa, there is a growing concern about the overexploitation and subsequent degradation of natural resources. In many regions such as the Sahel, where rural populations predominantly rely on forest resources for survival, continuing anthropogenic pressure on vegetation and soils is leading to both severe land degradation and low productivity of farming systems (Gijsbers et al., 1994; Timmer et al., 1996).

Tree and shrub legumes are pioneer species that are widely recognised to play important roles during the early phases of the restoration process. Many of them, like native Acacia and Faidherbia species, have the ability to form $\mathrm{N}_{2}$-fixing nodules in association with rhizobia (Dreyfus and
Dommergues, 1981; Workman, 1986; Ndoye et al., 1995). These $\mathrm{N}_{2}$-fixing trees (NFTs) may directly meet their $\mathrm{N}$ requirements from symbiotically fixed $\mathrm{N}$, which allows them to thrive even on soils of low nutrient status. In addition, NFTs have potential for fuel wood and various other useful products such as pharmaceuticals, gums, and both N-rich fodder and mulch.

A substantial body of work has highlighted the importance of introducing appropriate $\mathrm{N}_{2}$-fixing systems to improve plant establishment and growth (Galiana et al., 1994, 1998; Gueye et al., 1997; Sutherland et al., 2000; Lesueur and Sarr, 2008). There are generally strong interactions between NFTs and root-nodule rhizobia, resulting in a key factor that determines the efficiency of the nodulation and $\mathrm{N}_{2}$-fixation (Bala and Giller, 
2001; Thrall et al., 2007). Estimates of indigenous rhizobia in soil samples collected from various sites were reported to be dependent upon the trap host species (Odee et al., 1995; Bala et al., 2003), indicating specific requirements of NFTs for rhizobial strains to form nodules. Other studies have reported that host germplasm $\mathrm{x}$ rhizobial strain interactions also influence the symbiotic properties at the provenance level within NFTs such as Acacia mangium (Galiana et al., 1994, Rahman et al., 2000), A. nilotica and A. Senegal (Sarr et al., 2005a, 2005b), and $F$. albida (Sniezko and Stewart, 1989; Dianda and Chalifour, 2002). These findings suggest that enhanced $\mathrm{N}_{2}$-fixation may be achieved by selecting host provenance $\mathrm{x}$ rhizobial isolate combinations. Awonaike et al. (1992) and Dommergues (1995) recommended that selection for improved symbiotic traits should be best based on knowledge of the quantitative assessment of such interactions. In Gliricidia - rhizobium symbiosis for example, Awonaike et al. (1992) found that the host-germplasm $x$ strain interaction accounted for more than $50 \%$ of the total variability in the $\mathrm{N}_{2}$-fixation.

$F$. albida is a common NTF with a restoration value that will likely benefit from symbiotic improvement because the species consistently ranks among those with low potential for $\mathrm{N}_{2}$-fixation, as evaluated using ${ }^{15} \mathrm{~N}$ methods (Sanginga et al., 1990; Ndoye et al., 1995; Gueye et al., 1997; Sutherland et al., 2000). However, there are genotypic differences in the $\mathrm{N}_{2}$-fixing potential of $F$. albida, which suggest the possibility to select pairs of symbionts for enhancing $\mathrm{N}_{2}$-fixation (Sanginga et al., 1990). In a previous screening for better symbiosis, Gueye et al. (1997) used seven $F$. albida provenances and only one effective strain as inoculant in the nursery; the best one was subsequently transplanted in the field using another effective rhizobial strain for inoculation. The suitability of this approach, which implies the separate selection of the host germplasm and rhizobia, however, needs to be further confirmed because the interaction component of the variability was clearly overlooked. We hypothesised that if this procedure is relevant, then the provenance $\mathrm{x}$ strain interaction should account for only minor contributions to variations relative to host and rhizobial factors.

Therefore, the present study aimed at investigating the effects of host genotype $\mathrm{x}$ rhizobium strain interactions on the growth performance and $\mathrm{N}$ nutrition in $F$. albida. The experiment used several $F$. albida provenances and the rhizobial strain already tested in the nursery by Gueye et al. (1997), as well as other rhizobial isolates derived from root-nodules of $F$. albida. The objective was to determine whether there are symbioticrelated traits for which the dual selection procedure should be used for optimal $\mathrm{N}_{2}$ fixing efficiency.

\section{MATERIALS AND METHODS \\ Plant material and cultivation}

Four provenances of $F$. albida were used in this study: Pire supplied by D.R.P.F. (Direction des Recherches sur les Productions Forestières) and Kabrousse (our collection), both from Senegal, and Dem and Gomblora, both obtained from C.N.S.F. (Centre Nationale des Semences Forestières), Burkina Faso. Seeds from Kabrousse were collected from one $F$. albida mother tree located in paddy fields in southern Senegal. Seeds of each provenance were scarified for one hour in concentrated $\mathrm{H}_{2} \mathrm{SO}_{4}$ and thoroughly rinsed with sterile distilled water until all traces of acid were removed. The seeds were then placed on sterile agar/water $(0.8 \% \mathrm{v} / \mathrm{w})$ plates and germinated in the dark at room temperature. After $48 \mathrm{~h}$ seedlings were aseptically transferred to tubes $(180 \times 16 \mathrm{~mm})$ (one per tube) containing agar slant of $\mathrm{N}$ deficient Jensen's medium (Vincent, 1970). The plants were subsequently watered using sterile distilled water.

\section{Rhizobium strains and inoculation}

Five rhizobial strains, ORS136, ORS167, ORS179 and ORS188 (Dupuy and Dreyfus, 1992) isolated from $F$. albida in Senegal, and Z3 isolated from the same species in Burkina Faso, were used. These strains originated from soils sampled at different depths. The strains were cultured in yeast extract mannitol broth (Vincent, 1970) and incubated at $28{ }^{\circ} \mathrm{C}$ for 5 days. The seedlings were inoculated with $100 \mu$ of the broth cultures containing approximately $10^{8}$ cells. $\mathrm{ml}^{-1}$. 


\section{Experimental design and treatments}

The experiment was a factorial combination of the provenances, and the rhizobium strains including an uninoculated control. The overall experiment comprised 24 treatments each with five replications. After inoculation, the tubes were arranged in a completely randomised design in a growth room at $30{ }^{\circ} \mathrm{C}$.

\section{Harvest}

Two months after inoculation, nodule number, plant height and tap root length were recorded. The plants were separated into shoots, roots and nodules. Each plant part was oven-dried for $48 \mathrm{~h}$ at $65{ }^{\circ} \mathrm{C}$ and weighed. Because biomass was limited, dried shoots from each treatment were randomly separated into two replicates, and finely ground. The nitrogen content was determined by the Kjeldahl method. Amounts of $\mathrm{N}$ derived from $\mathrm{N}_{2}$-fixation were estimated using the total $\mathrm{N}$ difference method (Danso, 1995).

\section{Data analysis}

For each variable, data were tested for homogeneity of variance and then subjected to a two-way analysis of variance (ANOVA) using the General Linear Model procedures (GLM) (SAS, 1990). Wherever the provenance $\mathrm{x}$ strain interaction was significant, data for uninoculated treatments were discarded. Means squares of the ANOVA were further used to derive the appropriate variance components related to each factor (provenance, strain and provenance $\mathrm{x}$ strain, respectively). Values were expressed as proportion of the total variance to illustrate the relative contributions of these variance components to the overall symbiotic variability. Means were compared using Duncan's multiple range test $(\mathrm{P}<0.05)$.

\section{RESULTS}

\section{Plant growth}

Faidherbia albida seedlings grown in test tubes typically developed vigorous tap roots and thin lateral roots usually embedded in the agar slant. However, there were large variations in seedling morphological traits at two months. The provenances from Senegal showed greater seedling size than those from Burkina Faso, with the highest values (means overall inoculation treatments) for plant height, tap root length, and shoot and root dry weights (DWs) $(\mathrm{P}<0.001$; Table 1). Kabrousse performed best, with more than 4 -5 times higher DWs than the poorest performing Gomblora $(\mathrm{P}<0.001)$. In contrast, Dem and Gomblora showed no significant differences in plant growth characteristics. Significant differences also occurred between the inoculation treatments in seedling growth parameters. The uninoculated control plants gave the lowest means (averaged overall provenances) for the measured growth parameters $(\mathrm{P}<0.001$; Table 2$)$.

\section{Nodulation}

The seedlings were well nodulated in all treatments except for the uninoculated control plants that were free of nodules. Nodulation parameters, however, varied significantly among the provenances and also among the strains (all $\mathrm{P}<0.001$ ). The Kabrousse provenance had the highest mean number of nodules and DW of nodules (36.9 nodules and $25.5 \mathrm{mg}$ plant $^{-1}$ ) (Table 1). The three other provenances had almost similar nodule number in the range of 22.9 to 27.1 nodules plant ${ }^{-1}$, except that the mean nodule DW was significantly greater for the Pire provenance $\left(20.2 \mathrm{mg} \mathrm{plant}^{-1}\right)$. Over all the provenances, the nodule number was the greatest for seedlings inoculated with the ORS167 strain from Senegal, and the lowest for those inoculated with the Z3 strain from Burkina Faso (Table 2). However, seedlings inoculated with the ORS136 strain gave the highest DW of nodules $(29 \mathrm{mg}$ ), which was similar to the value recorded for the ORS167inoculated seedlings (25.3 mg.plant ${ }^{-1}$ ).

\section{Shoot $\mathbf{N}$ content and $\mathbf{N}_{2}$-fixation}

The shoot $\mathrm{N}$ concentration $(\% \mathrm{~N})$ varied significantly among the strains $(\mathrm{P}<0.001)$, whereas the shoot total $\mathrm{N}$ uptake was influenced by both provenance and strain (all $\mathrm{P}<0.001$ ). Moreover, provenance $\mathrm{x}$ strain interaction was significant for both shoot $\mathrm{N}$ content $(\mathrm{P}<0.01)$ and $\mathrm{N}_{2}$ fixation $(\mathrm{P}<0.05)$. However, these interactions appeared to account for relatively minor contributions to the overall variability (6 and $10 \%$, respectively) (Table 3). Among-provenances variation had the highest contribution $(70.6 \%)$ to the total variability in shoot total $\mathrm{N}$ uptake. Similarly, among-strains variation represented $71.2 \%$ 
M. DIANDA et al. / Int. J. Biol. Chem. Sci. 3(4): 716-724, 2009

Table 1: Height, dry weight (DW), nodulation, and shoot nitrogen $(\mathrm{N})$ uptake of the four provenances at two months.

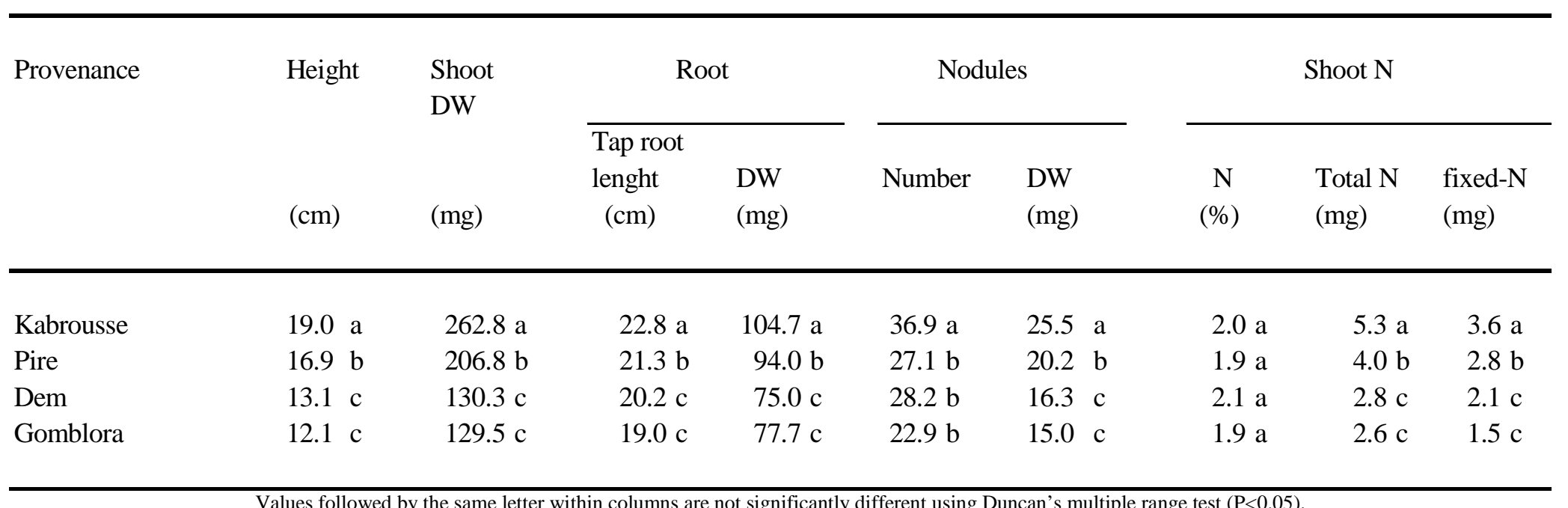

Values followed by the same letter within columns are not significantly different using Duncan's multiple range test $(\mathrm{P}<0.05)$. 
M. DIANDA et al. / Int. J. Biol. Chem. Sci. 3(4): 716-724, 2009

Table 2: Effects of five rhizobium strains on height, dry weight (DW), nodulation, and shoot nitrogen (N) uptake of two-month old seedlings of F. Albida..

\begin{tabular}{|c|c|c|c|c|c|c|c|c|}
\hline \multirow{2}{*}{$\begin{array}{l}\text { Rhizobium } \\
\text { strain }\end{array}$} & \multirow{2}{*}{$\begin{array}{l}\text { Height } \\
(\mathrm{cm})\end{array}$} & \multirow{2}{*}{$\begin{array}{l}\text { Shoot } \\
\text { DW } \\
(\mathrm{mg})\end{array}$} & \multicolumn{2}{|c|}{ Root } & \multicolumn{2}{|c|}{ Nodules } & \multicolumn{2}{|c|}{ Shoot N } \\
\hline & & & $\begin{array}{l}\text { lenght } \\
(\mathrm{cm})\end{array}$ & $\begin{array}{l}\mathrm{DW} \\
(\mathrm{mg})\end{array}$ & Number & $\begin{array}{l}\text { DW } \\
(\mathrm{mg})\end{array}$ & $(\%)$ & $(\mathrm{mg})$ \\
\hline ORS 136 & $15.7 \mathrm{ab}$ & $185.1 \mathrm{ab}$ & $21.4 \mathrm{~b}$ & $81.4 \mathrm{c}$ & $31.0 \mathrm{bc}$ & $29.0 \mathrm{a}$ & $2.7 \mathrm{a}$ & $5.1 \mathrm{a}$ \\
\hline ORS 167 & $15.2 \mathrm{ab}$ & $189,0 \mathrm{ab}$ & $23.4 \mathrm{a}$ & $104.5 \mathrm{a}$ & $45.2 \mathrm{a}$ & $25.3 \mathrm{ab}$ & $1.8 \mathrm{c}$ & $3.6 \mathrm{~b}$ \\
\hline ORS 179 & $14.6 \mathrm{~b}$ & $182.5 \mathrm{~b}$ & $20.6 \mathrm{~b}$ & $83.1 \mathrm{c}$ & $34.7 \mathrm{bc}$ & $22.3 \mathrm{bc}$ & $2.0 \mathrm{bc}$ & $3.5 \mathrm{~b}$ \\
\hline ORS 188 & $17.0 \mathrm{a}$ & $207.5 \mathrm{a}$ & $20.7 \mathrm{~b}$ & $98.8 \mathrm{ab}$ & $35.1 \mathrm{bc}$ & $20.5 \mathrm{bc}$ & $1.8 \mathrm{c}$ & $3.7 \mathrm{ab}$ \\
\hline $\mathrm{Z3}$ & $17.1 \mathrm{a}$ & $206.7 \mathrm{a}$ & $20.5 \mathrm{~b}$ & $91.2 \mathrm{bc}$ & $26.2 \mathrm{c}$ & $17.5 \mathrm{c}$ & $2.2 \mathrm{~b}$ & $4.5 \mathrm{ab}$ \\
\hline Control & $11.9 \mathrm{c}$ & $117.7 \mathrm{c}$ & $18.3 \mathrm{c}$ & $66.6 \mathrm{~d}$ & $0.0-$ & - & $1.3 \mathrm{~d}$ & $1.6 \mathrm{c}$ \\
\hline
\end{tabular}

Values followed by the same letter within columns are not significantly different using Duncan's multiple range test $(\mathrm{P}<0.05)$ 
Table 3: Summary of analysis of variance (ANOVA) and components of total phenotypic variance for shoot nitrogen concentration $(\% \mathrm{~N})$ and total shoot $\mathrm{N}$ uptake in $F$. albida / rhizobium symbiosis.

\begin{tabular}{lllll}
\hline Source & ${ }^{\mathrm{a}} \mathrm{Df} \quad{ }^{\mathrm{b}} \mathrm{MS}$ & Variance components & $\begin{array}{c}\text { Percentage of } \\
\text { total phenotypic } \\
\text { variance }\end{array}$ \\
& & Estimates & Values & \\
\hline
\end{tabular}

Shoot $\mathrm{N}$ concentration $(\% \mathrm{~N})$

$\begin{array}{lclllc}\text { Provenance }(\mathrm{P}) & 3 & 1302.5 & 1053.0 / 10 & 105.3 & 5.6 \\ \text { Strain }(\mathrm{S}) & 4 & 10890.2 & 10640.6 / 8 & 1330.1 & 71.2 \\ \text { PxS } & 12 & 615.8 & 366.2 / 2 & 183.1 & 9.8 \\ \text { Error } & 20 & 249.6 & 249.6 & 249.6 & 13.4 \\ \text { Total } & 39 & & & 1868.0 & 100.0\end{array}$

Total shoot $\mathrm{N}\left(\mathrm{mg}_{\mathrm{plant}}{ }^{-1}\right)$

$\begin{array}{lclllc}\text { Provenance }(\mathrm{P}) & 3 & 202845.7 & 200422.9 / 10 & 20042.3 & 70.7 \\ \text { Strain }(\mathrm{S}) & 4 & 36646.6 & 34223.7 / 8 & 4278.0 & 15.1 \\ \text { PxS } & 12 & 5635.7 & 3212.8 / 2 & 1606.4 & 5.7 \\ \text { Error } & 20 & 2422.8 & 2422.8 & 2422.8 & 8.5 \\ \text { Total } & 39 & & & 28349.5 & 100.0\end{array}$

${ }^{\mathrm{a}}$ Degree of freedom; ${ }^{\mathrm{b}}$ Mean square

of the total variability in the $\% \mathrm{~N}$. Furthermore, the strain component of variance contributed more to the total variability in total $\mathrm{N}(15.1 \%)$ than did the provenance component to the $\% \mathrm{~N}(5.7 \%)$.

The provenances showed almost similar shoot $\% \mathrm{~N}$, while both total shoot $\mathrm{N}$ and amount of $\mathrm{N}$ derived from fixation followed similar trends as for plant growthtraits (Table 1). The Kabrousse provenance, with $5.3 \mathrm{mg} \mathrm{N}$ plant $^{-1}$ (from which $3.6 \mathrm{mg}$ was fixed-N), performed the best in shoot $\mathrm{N}$ uptake and $\mathrm{N}_{2}$-fixation, followed by Pire, both from Senegal. Total shoot $\mathrm{N}$ and estimates of $\mathrm{N}_{2}$-fixation were the lowest for the two provenances from Burkina Faso (Dem and Gomblora). The shoot \% $\mathrm{N}$ and total shoot $\mathrm{N}$ uptake were consistently lowest for the control plants (table 2). Among the inoculated treatments, the shoot $\% \mathrm{~N}$ was greatest for the ORS136-inoculated plants. There were three most efficient strains (ORS136, ORS188 and $\mathrm{Z3}$ ) in total shoot $\mathrm{N}$ accumulation with values ranging from 3.7 to $5.1 \mathrm{mg}^{\text {. plant }}{ }^{-1}$ (Table 2).

\section{DISCUSSION}

In this study, single strain inoculation of $F$. albida seedlings improved plant growth characteristics as well as shoot $\mathrm{N}$ content, confirming the ability of this leguminous tree species to derive ample benefits from established $\mathrm{N}_{2}$-fixing symbiosis under conditions of extreme N scarcity (Dupuy and Dreyfus, 1992; Njiti and Galiana, 1996). There were also large variations among the provenances and the inoculants in all $\mathrm{N}_{2^{-}}$ fixation traits, which suggest great possibilities of improvement through selection for enhanced symbiotic properties. It is clear however, that this potential should be considered with caution since our results were derived from plants when only two months. Nevertheless, it could be valued when selecting provenances and rhizobia at a very earlier stage of plant growth (for example, in preliminary screenings of large materials).

In fact, the provenances used here are part of a larger range that was previously tested for six months in the nursery by Gueye 
et al. (1997). While the objective of these authors was to improve $\mathrm{N}_{2}$-fixation by selecting the host genotypes, our study aimed at further extending this earlier work by providing a basis for predicting to what extent the method they used for selection can be successful. Interestingly, our results showed that significant provenance $\mathrm{x}$ strain interactions also occur in some important selection criteria like shoot $\mathrm{N}$ concentration $(\% \mathrm{~N})$ and total shoot N. Even though this suggests that combinations of provenances and rhizobial strains should be selected (Galiana et al., 1994; Dommergues, 1995), the results further showed that the contributions of these effects to the corresponding phenotypic variances were rather low (6$10 \%)$, compared with similar values $(>50 \%)$ reported by Awonaike et al. (1992) in Gliricidia sepium.

If the interaction effect showed above is assumed to be negligible, then the information useful for devising a method for selection would rely solely on host germplasm and rhizobia. The provenance factor appeared to be the major determinant $(70.7 \%)$ of the total phenotypic variation in total shoot $\mathrm{N}$ while the bacterial factor contributed the most $(71.2 \%)$ to variation in shoot $\% \mathrm{~N}$. The relatively low contribution of the host factor to the variability in shoot $\% \mathrm{~N}$ indicates that inherently low provenance diversity in $\% \mathrm{~N}$ is to be expected in F. albida. This is consistent with findings that when raised under uniform conditions, provenances of $F$. albida derived from the same native range tend to have similar shoot $\mathrm{N}$ concentrations (Sniezko and Stewart, 1989). Moreover, our results demonstrated that the variation in $\% \mathrm{~N}$ was mainly related to strains' effects. As shown by previous studies a wide range of symbiotic effectiveness occurs among rhizobial populations in soils (Bala et Giller, 2001; Thrall et al., 2007), which may account for the variation in seedling shoot $\% \mathrm{~N}$ both among nurseries and between provenances within nurseries observed by Sniezko and Stewart (1989). This study also showed a clear relationship between the amount of shoot $\mathrm{N}$ uptake and the growth ability of the host genotype, which supports the findings of Sanginga et al. (1990) suggesting growth performance to be a major determinant of $\mathrm{N}$ cycling in $F$. albida and other $\mathrm{N}_{2}$-fixing trees.
From the current results therefore, a two-step screening procedure consisting of identifying the best growth performer among provenances on one hand, and selecting the most effective strain as microbial inoculant on the other hand, seems to be a better way to enhance $\mathrm{N}_{2}$-fixation. This is in accordance with the work of Gueye et al. (1997) who used a similar approach by first selecting provenances of $F$. albida for improved $\mathrm{N}_{2^{-}}$ fixation. There were clear-cut differences between $F$. albida provenances in growth patterns and nodulation parameters with Kabrousse being the best performer. The ranking of the four provenances based on shoot DWs was almost similar to that reported at six months (on the basis of plant parts DWs) (Gueye et al., 1997), indicating that the above ground biomass of seedlings can be considered as a reliable criterion for early selection of provenances in F. albida.

There were also consistent growth responses to inoculation regardless of the provenance, which suggest that all the strains used were actively fixing. The broad grouping of inoculants based on seedling growth traits indicates that they had possibly similar levels of effectiveness. The extent of growth responses, however, was much greater than that reported for effective strains by Njiti et Galiana (1996). Dupuy and Dreyfus (1992) using the ARA (acetylene reduction activity) method reported the strains isolated in Senegal (ORS136, ORS167, ORS179 and ORS188) as being highly effective. The values of shoot $\% \mathrm{~N}$ indicate that the strain ORS136 was the most outstanding. Such differences between studies and criteria in the estimates of symbiotic properties of rhizobial isolates, stresses the need to screen at least several proven effective strains in order to ensure that the best ones are further used as inoculants. Selecting but one strain can be risky because strains may not be adapted to all environments, or may lose effectiveness (Sutherland et al., 2000; Lesueur and Sarr, 2008).

Unlike plant genotypes for which growth traits provide relatively good criteria for selection, such morphological features are proven less reliable for assessing the effectiveness of rhizobial strains, largely because plant response to inoculation can be restricted by inappropriate environmental 
factors (Deans et al., 1993; Sutherland et al., 2000). In experiments using ${ }^{15} \mathrm{~N}$ techniques however, the nodule enrichment in ${ }^{15} \mathrm{~N}$ relative to shoots has been shown to provide good estimates of symbiotic effectiveness in several $\mathrm{N}_{2}$-fixing tree species including $F$. albida (Sutherland et al., 2000). Similarly, our observation above relating the $\% \mathrm{~N}$ to effectiveness of strains show that under $\mathrm{N}$ free conditions, shoot $\mathrm{N}$ concentration likely provides a more accurate criterion for screening strains than growth traits measurements. However, because $\mathrm{N}_{2}$-fixing symbiosis in $F$. albida can vary greatly in their ability to tolerate combined $\mathrm{N}$ stresses (Dianda and Chalifour, 2002), N concentration may be a less suitable $\mathrm{N}_{2}$ fixation criterion under $\mathrm{N}$-rich conditions.

\section{ACKNOWLEDGEMENTS}

We gratefully thank Mr. Vautour Mathieu David and Mr. Hien Romarique for correcting the English text.

\section{REFERENCES}

Awonaike KO, Hardarson G, Kumarasinghe KS. 1992. Biological nitrogen fixation of Gliricidia sepium / Rhizobium symbiosis as influenced by plant genotype, bacterial strain and their interactions. Trop. Agric. (Trinidad), 69: 381-385.

Bala A, Giller KE. 2001. Symbiotic specificity of tropical tree rhizobia for host legumes. New Phytol., 149: 495-507.

Bala A, Murphy PJ, Osunde AO, Giller KE. 2003. Nodulation of tree legumes and the ecology of their native rhizobial populations in tropical soils. Appl. Soil Ecol., 22: 211-223.

Danso SKA. 1995. Assessment of biological nitrogen fixation. Fert. Res., 42: 33-41.

Deans JD, Ali OM, Lindley DK, Nour HOA. 1993. Rhizobial nodulation of Acacia tree species in Sudan: soil inoculum potential and effects of peat. J. Trop. For. Sci., 6: 56-64.

Dianda M, Chalifour F-P. 2002. Effets du N minéral et du génotype de plante sur la croissance et la nodulation de Faidherbia albida. Can. J. Bot., 80: 241-254.

Dommergues YR. 1995. Nitrogen fixation by trees in relation to soil nitrogen economy. Fert. Res., 42: 215-230.
Dreyfus BL, Dommergues YR. 1981. Nodulation of Acacia species by fast- and slow-growing tropical strains of Rhizobium. Appl. Environ. Microbiol., 41: 97-99.

Dupuy NC, Dreyfus BL. 1992. Bradyrhizobium populations occur in deep soil under the leguminous tree $F$. albida. Appl. Environ. Microbiol., 58: 24152419.

Galiana A, Gnahoua GM, Chaumont J, Lesueur D, Prin Y, Mallet B. 1998. Improvement of nitrogen fixation in Acacia mangium through inoculation with rhizobium. Agrofor. Syst., 40: 297-307.

Galiana A, Prin Y, Mallet B, Gnahoua GM, Poitel M, Diem HG. 1994. Inoculation of Acacia mangium with alginate beads containing selected Bradyrhizobium strains under field conditions: long-term effect on plant growth and persistence of the introduced strains in soil. Appl. Environ. Microbiol., 60: 3974-3980.

Gijsbers HJM, Kessler JJ, Knevel MK. 1994. Dynamics and natural regeneration of woody species in farmed parklands in the Sahel region (Province of Passoré, Burkina Faso). For. Ecol. Manage., 64: 1-12.

Gueye M, Ndoye I, Dianda M, Danso SKA, Dreyfus B. 1997. Active $\mathrm{N}_{2}$-fixation in several Faidherbia albida provenances. Arid Soil Res. Rehab., 11: 63-70.

Lesueur D, Sarr A. 2008. Effects of single and dual inoculation with selected mycrosymbionts (rhizobia and arbuscular mycorrhizal fungi) on field growth and nitrogen fixation of Calliandra calothyrsus Meissn. Agrofor. Syst., 73: 37-45.

Ndoye I, Gueye M, Danso SKA, Dreyfus B. 1995. Nitrogen fixation in Faidherbia albida, Acacia raddiana, Acacia senegal and Acacia seyal estimates using the ${ }^{15} \mathrm{~N}$ isotope dilution technique. Plant Soil, 172: $175-180$.

Njiti CF, Galiana A. 1996. Symbiotic properties and Rhizobium requirements for effective nodulation of five tropical dry zone acacias. Agrofor. Syst., 34: 265275.

Odee DW, Sutherland JM, Kimiti JM, Sprent JI. 1995. Natural rhizobial populations and nodulation status of woody legumes 
growing in diverse Kenyan conditions. Plant Soil, 173: 211-224.

Rahman GMM, Nara K, Hogetsu T. 2000. Assay of host specificities of rhizobial strains on Acacia mangium from different provenances and different Acacia species. Bull. Tokyo Univ. For., 103: 333-337.

Sanginga N, Danso SKA, Zapata F, Bowen GD. 1990. Influence of reference trees on $\mathrm{N}_{2}$-fixation estimates in Leucaena leucephala and Acacia albida using ${ }^{15} \mathrm{~N}$ labelling techniques. Biol. Fert. Soils, 9: 341-346.

Sarr A, Diop B, Peltier R, Neyra M, Lesueur D. 2005a. Effects of rhizobial inoculation methods and host plant provenances on nodulation and growth of Acacia senegal and Acacia nilotica. New Forests, 29: 7587.

Sarr A, Neyra M, Abdeljalil M, Houeibib O, Ndoye I, Oihabi A, Lesueur D. 2005b. Rhizobial populations in soils from natural Acacia senegal and Acacia nilotica forests in Mauritania and the Senegal river valley. Microbial Ecology, 50:152-162.

SAS. 1990. SAS procedures guide, version 6 $\left(3^{\text {rd }}\right.$ edn). SAS Institute Inc.: Cary.
Sniezko RA, Stewart HTL. 1989. Range-wide provenance variation in growth and nutrition of Acacia albida seedlings propagated in Zimbabwe. For. Ecol. Manage., 27: 179-197.

Sutherland JM, Odee DW, Muluvi GM, McInroy SG, Patel A. 2000. Single and multi-strain rhizobial inoculation of African acacias in nursery conditions. Soil Biol. Biochem., 32: 323-333.

Thrall P, Slattery JF, Broadhurst LM, Bickford S. 2007. Geographic patterns of symbiont abundance and adaptation in native Australian Acacia-rhizobia interactions. Journal of Ecology, 95: 1110-1122.

Timmer LA, Kessler JJ, Slingerland M. 1996. Pruning of néré (Parkia biglobosa (Jacq.) Benth.) on the farmlands of Burkina Faso, West Africa. Agrofor. Syst., 33: 87-98.

Vincent JM. 1970. A Manual for the Practical Study of the Root Nodule Bacteria (IBP handbook $\mathrm{n}^{\circ}$ 15). Black Scientific Publications: Oxford.

Workman SW. 1986. Nodulation trials with selected arboreal legumes of Burkina Faso, West Africa. Nitrogen fixing Tree Res. Rep., 5: 7-8. 